\title{
Seismic Behavior of the Low-rise Shear Wall with CFST Frame and Embedded Steel-plate
}

\author{
Wang Yaohong ${ }^{1, *}$, Wu Dingyan ${ }^{2}$ and Cao Wanlin ${ }^{3}$ \\ ${ }^{I}$ Civil Engineering Institute, Inner Mongolia University of Technology, Hohhot, Inner Mongolia, 010051, P.R. China \\ ${ }^{2}$ Asia-pacific Institute of Construction SciTech Information Co., Ltd, Beijing, 100120, P.R. China \\ ${ }^{3}$ College of Architecture and Civil Engineering, Beijing University of Technology, Beijing, 100124, P.R. China
}

\begin{abstract}
In this paper, two low-rise shear wall specimens are tested on the shaking table, one is shear wall with CFST frame and embedded steel-plate, the other one is no concrete outside the steel-plate in comparison of the first one. The reduced scale of the two specimens is $1 / 12$. The seismic wave "Taft" is input in the shaking table test. Based on the experiment, the author conducts the time history analysis (including elastic stage and plastic stage) of the specimens. The calculated results and measured results are compared.
\end{abstract}

Keywords: CFST frame, shaking table test, steel-plate, time history analysis.

\section{INTRODUCTION}

It is very important to enhance the seismic ability of shear walls which are the primary lateral load resisting elements in high-rise buildings. In order to meet requirements of the modern constructions whose heights continue to increase, more and more new kinds of shear wall have appeared.

Steel-plate shear wall is a new kind of lateral force resisting component which has very good seismic ability. It has been more and more widely used in high-rise buildings of developed countries. But this kind of shear wall is more prone to out-of-plane displacement, so it is not perfect [1]. Concrete-filled steel tube (CFST) columns have studied by many scholars in recent years. The studies prove that the columns have high bearing capacity. Based on the above results, this paper presents the shear wall with CFST frame and embedded steel-plate which focus on all the advantages of steel-plate shear walls and concrete-filled steel tube columns.

It is noted that this paper is subsidized by scientific research project of Inner Mongolia University of Technology (approved: X201414).

\section{EXPERIMENT}

In order to study the seismic behavior of the new kind of shear wall mentioned above, two low-rise shear wall specimens with same height to width ratio are tested on the shaking table. One specimen is shear wall with CFST frame and embedded steel-plate, the other one is no concrete outside the steel-plate in comparison of the first one. The characteristic of the two specimens are showed in Table 1. The concretefilled steel tubular frame is welded with steel-plate and linked to the concrete by steel connecters which are made by thin iron sheet.

Table 1. The characteristic of the two specimens.

\begin{tabular}{|c|c|c|c|}
\hline Number & $\begin{array}{c}\text { Reduced } \\
\text { scale }\end{array}$ & $\begin{array}{c}\text { Ratio of height } \\
\text { to width }\end{array}$ & Remarks \\
\hline \hline GBW1 & $1 / 12$ & 1.7 & $\begin{array}{c}\text { no concrete out- } \\
\text { side the steel-plate }\end{array}$ \\
\hline GBW2 & $1 / 12$ & 1.7 & \\
\hline
\end{tabular}

The compressive strength of concrete cubes is $34.2 \mathrm{Mpa}$, and the elastic modulus of concrete is $2.91 \times 10^{4} \mathrm{MPa}$. The mechanical properties of the other materials are showed in Table 2. The construction photograph of specimen GBW2 is showed in Fig. (1). The dimension details of the two specimens are showed in Fig. (2).

Table 2. Mechanical properties of steel tube and steel-plate.

\begin{tabular}{|c|c|c|c|}
\hline $\begin{array}{c}\text { The type of } \\
\text { material }\end{array}$ & Yield strength & $\begin{array}{c}\text { Ultimate } \\
\text { strength }\end{array}$ & $\begin{array}{c}\text { Elastic } \\
\text { Modulus }\end{array}$ \\
\hline \hline steel tube & $290 \mathrm{MPa}$ & $420 \mathrm{MPa}$ & $1.92 \times 10^{5} \mathrm{MPa}$ \\
\hline steel-plate & $215 \mathrm{MPa}$ & $329 \mathrm{MPa}$ & $1.90 \times 10^{5} \mathrm{MPa}$ \\
\hline
\end{tabular}

The shaking table test is carried out in building structure laboratory of Beijing University of Technology. The seismic wave "Taft" is input in the shaking table test. The situation of shaking table: the dimension is $3 \mathrm{~m} \times 3 \mathrm{~m}$, the weight is 6 ton, the maximum displacement is $\pm 127 \mathrm{~mm}$, the frequency range is $0.1-50 \mathrm{~Hz}$. According to the requirement of model 
similarity relation, the similarity coefficient of time is 0.289 , the time interval of seismic wave input is $0.00578 \mathrm{~s}$.

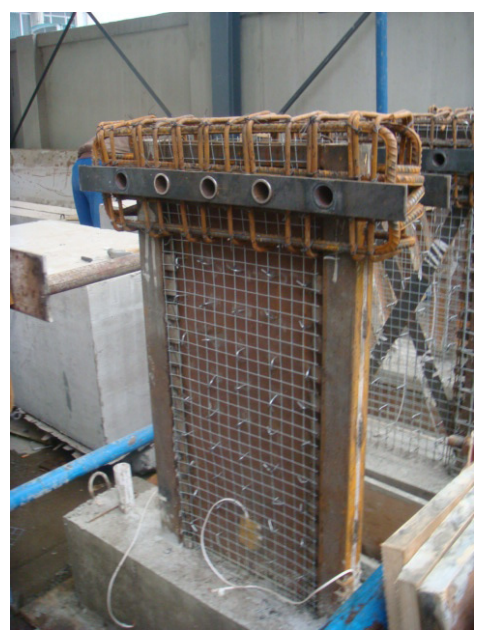

Fig. (1). Construction photograph of specimen GBW2.

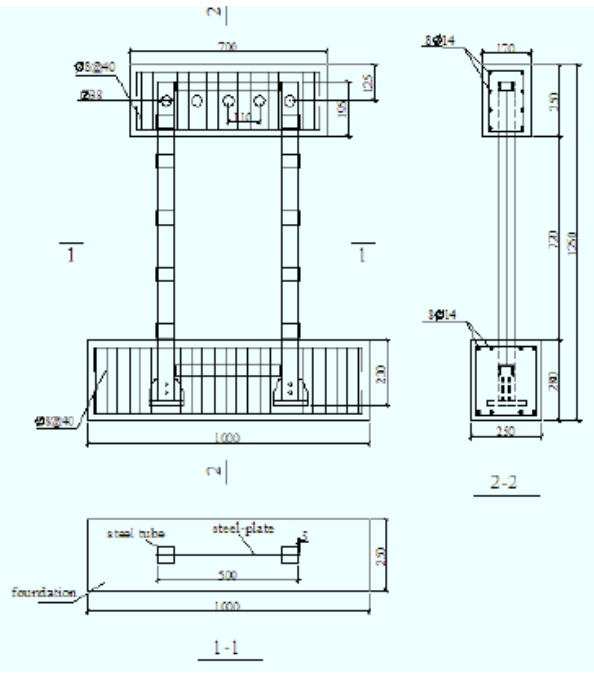

(a) specimen GBW1
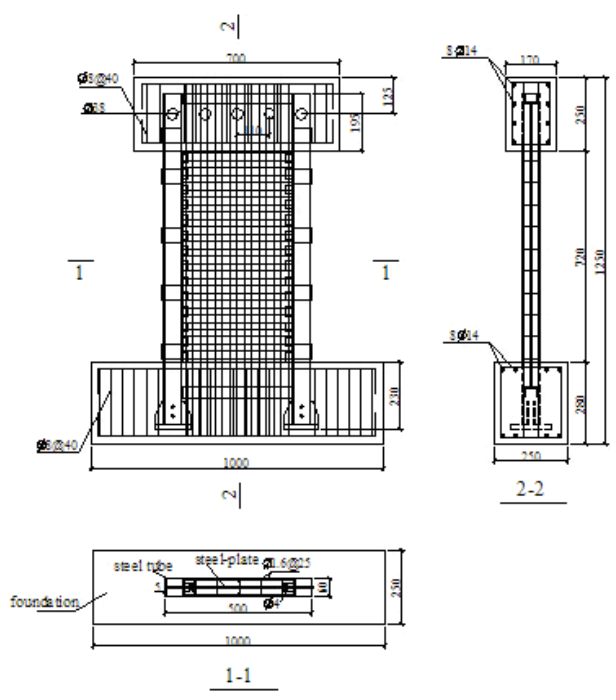

(b) specimen GBW2

Fig. (2). Dimension details of specimens.
The weight on the specimens is 7 tons. This weight can ensure that the specimens can be destroyed by the experiment. In order to achieve this purpose, the author design a steel groove which hold lots of clump weights inside. The clump weights are glued together by foam gum. The photo of steel groove is showed in Fig. (3).

The peak accelerations input in different working conditions are showed in Table 3. Photo of the test device is showed in Fig. (4). Lateral stiffness of the test device is much smaller than that of the specimens. So it is not concerned that the results of the experiment can be affected by the test device.

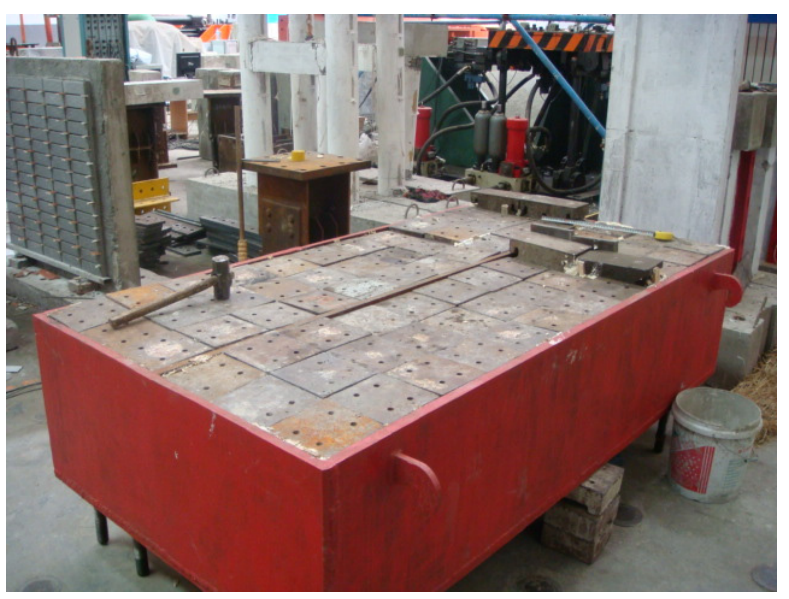

Fig. (3). Photo of the steel groove.

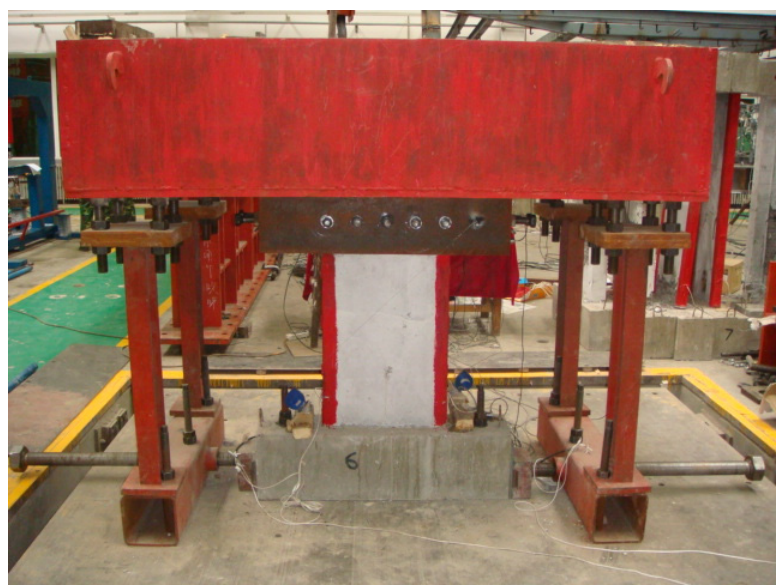

Fig. (4). Photo of the test device.

In the shaking table test, the shear wall with CFST frame and embedded steel-plate show a good seismic performance. It is because that the CFST frame and the steel-plate can provide enough resistance to deformation and avoid the specimen not to be collapsed too early or happening brittle failure in severe earthquake [2-5]. It is noted that the steelplate show large resistance to deformation and excellent energy dissipating capacity in the experiment. It is very propitious to enhance seismic behavior of the specimens.

The measured curves of natural vibration frequency-input peak acceleration are showed in Fig. (5). From the figure we can see that the natural vibration frequency of specimen GBW2 is even bigger than specimen GBW1 in similar peak 
Table 3. Test procedure.

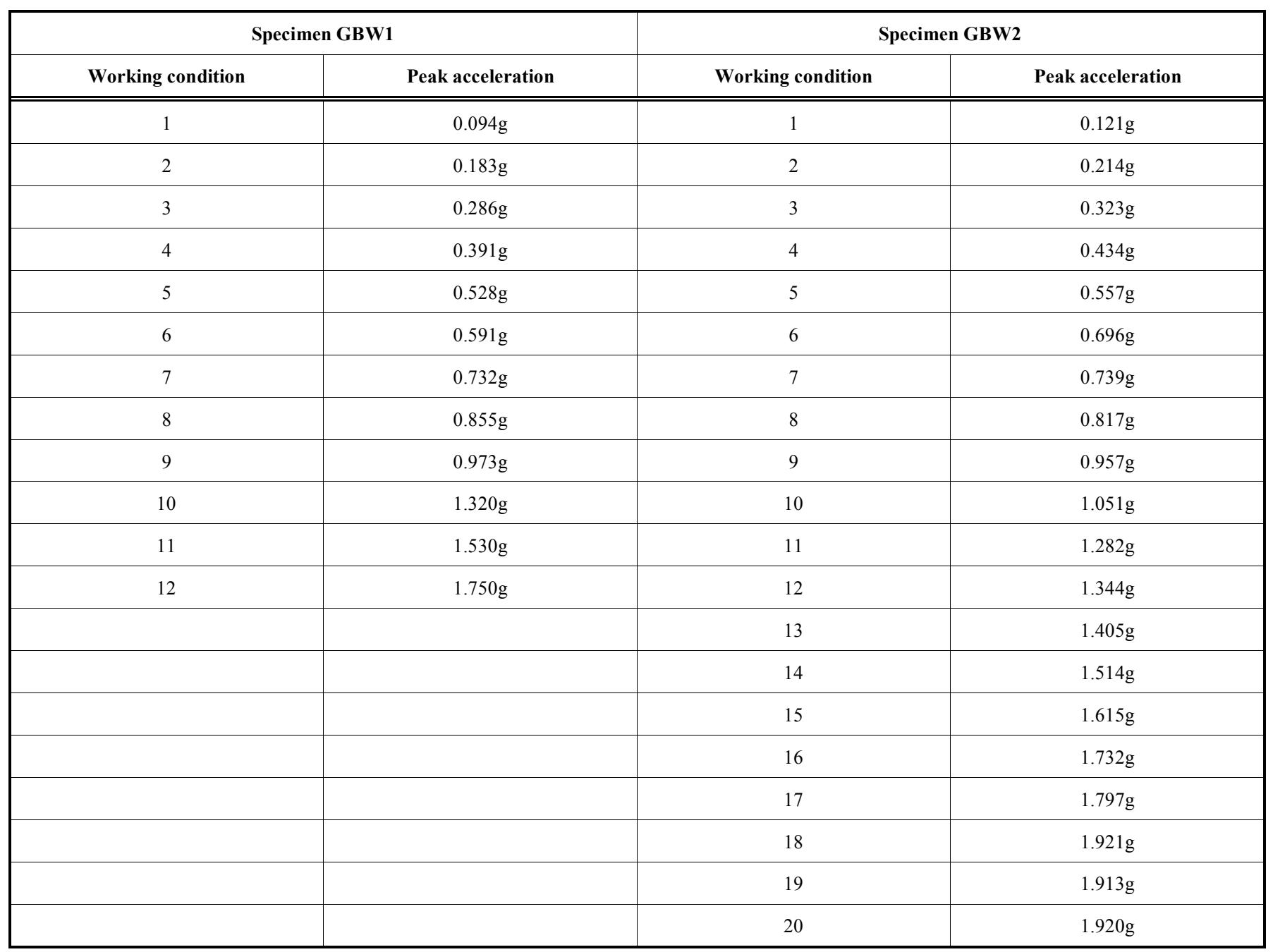

Remarks: It is noted that the seismic wave which was input in working condition 20 of specimen GBW2 is "Kerns".

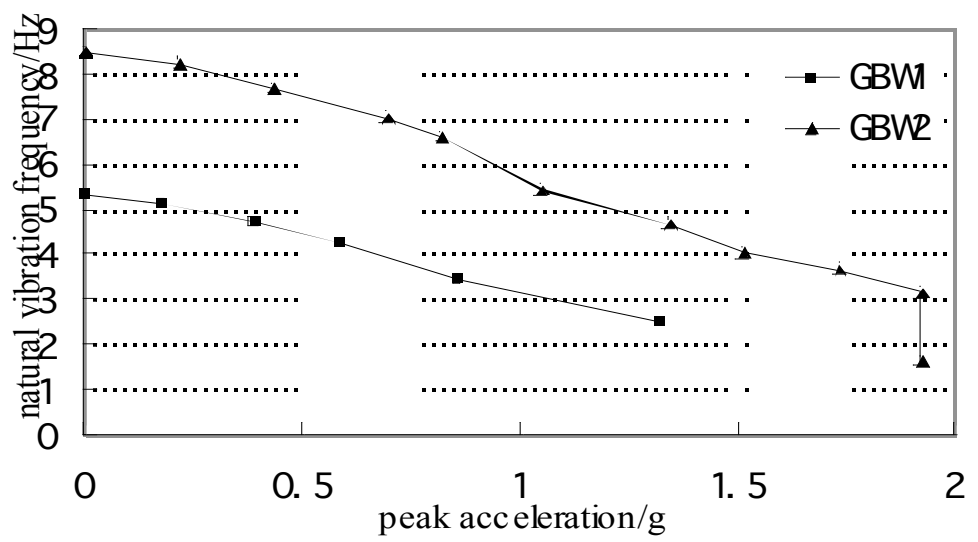

Fig. (5). Curves of natural vibration frequency-input peak acceleration.

acceleration. It is conducive to the specimen to maintain larger stiffness. It proves that the concrete outside the steelplate can fully enhance stiffness of specimen.

The curves of displacement response at the top of the specimens in similar peak accelerations are showed in Fig. (6). From the figure we can see that the displacement of specimen GBW2 is significantly smaller than specimen GBW1 in similar peak accelerations. The failure modes of the specimens are showed in Fig. (7). The results above prove that the concrete outside the steel-plate can fully decrease the displacement and avoid premature failure of the specimen [6]. 


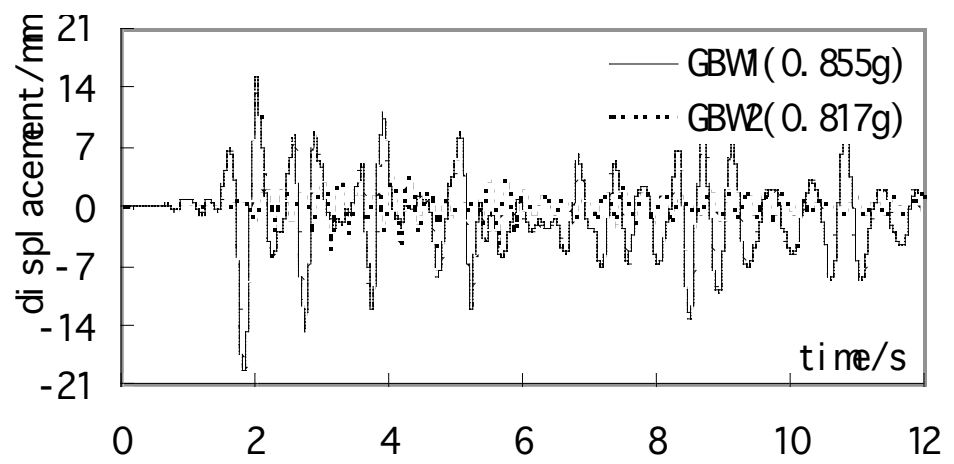

Fig. (6). Curves of displacement response at the top of the specimens in similar peak accelerations.

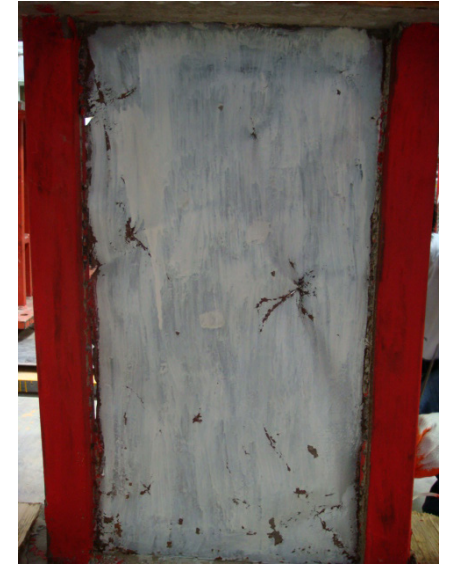

(a) GBW1

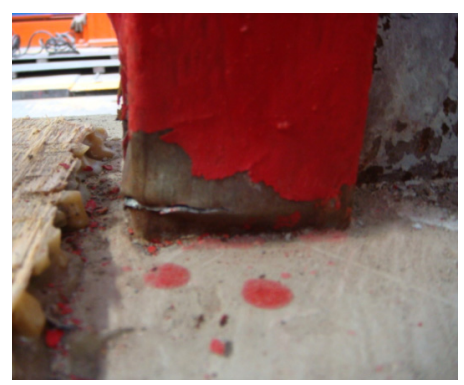

(c) Bottom of GBW1

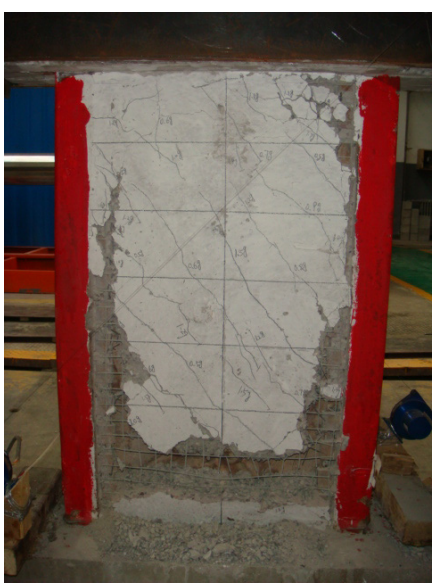

(b) GBW2

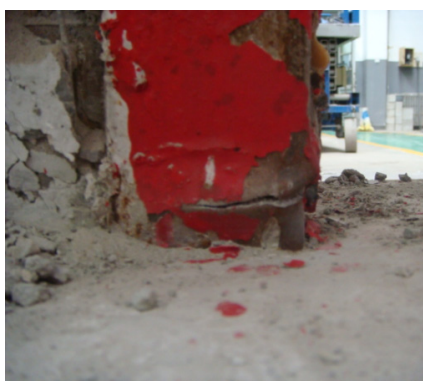

(d) Bottom of GBW2

Fig. (7). Failure modes of the specimens.

\section{ELASTIC-PLASTIC TIME HISTORY ANALYSIS}

Base on the results of the experiment, this paper has conducted the time history analysis (including elastic stage and plastic stage) of the specimens through using software "Abaqus" [7-9].

The Abaqus element library provides a powerful capability to build complicated geometric models. So researcher can use any combination of elements to build the structure models. Some special elements (such as line springs) use an approximate analytical solution to model nonlinear behavior.

In this paper, the concrete is simulated by element "C3D8R", the steel tubes and steel-plates are simulated by element "S4R", and the steel bars are simulated by element "C3D8R". The shapes of the specimens after elements have been meshed are showed in Fig. (8). The weight on the specimens is simulated by a thin quality layer.

The stress-strain curve of steels is showed in Fig. (9). We can use ideal elastic-plastic model to define the steels. The mathematical expressions of this model are as follows [10]:

$$
\begin{aligned}
& \sigma_{\mathrm{s}}=\left\{\begin{array}{cc}
E_{\mathrm{s}} \varepsilon_{\mathrm{s}} & \varepsilon_{\mathrm{s}} \leq \varepsilon_{\mathrm{e}} \\
-A \varepsilon_{\mathrm{s}}{ }^{2}+B \varepsilon_{\mathrm{s}}+C & \varepsilon_{\mathrm{e}}<\varepsilon_{\mathrm{s}} \leq \varepsilon_{\mathrm{e} 1} \\
f_{\mathrm{y}} & \varepsilon_{\mathrm{e} 1}<\varepsilon_{\mathrm{s}} \leq \varepsilon_{\mathrm{e} 2} \\
f_{\mathrm{y}}\left[\begin{array}{cc}
\left.1+0.6 \frac{\varepsilon_{\mathrm{s}}-\varepsilon_{\mathrm{e} 2}}{\varepsilon_{\mathrm{e} 3}-\varepsilon_{\mathrm{e} 2}}\right] & \varepsilon_{\mathrm{e} 2}<\varepsilon_{\mathrm{s}} \leq \varepsilon_{\mathrm{e} 3} \\
1.6 f_{\mathrm{y}} & \varepsilon_{\mathrm{s}}>\varepsilon_{\mathrm{e} 3}
\end{array}\right. \\
\varepsilon_{\mathrm{e}}=0.8 f_{\mathrm{y}} / E_{\mathrm{s}}, \quad \varepsilon_{\mathrm{e} 1}=1.5 \varepsilon_{\mathrm{e}}, \quad \varepsilon_{\mathrm{e} 2}=10 \varepsilon_{\mathrm{e} 1} \prime
\end{array}\right. \\
& \varepsilon_{\mathrm{e} 3}=100 \varepsilon_{\mathrm{e} 1}, \quad A=0.2 f_{\mathrm{y}} /\left(\varepsilon_{\mathrm{e} 1}-\varepsilon_{\mathrm{e}}\right)^{2},
\end{aligned}
$$




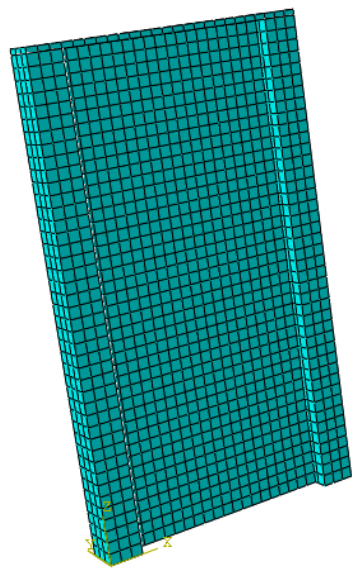

(a) GBW1

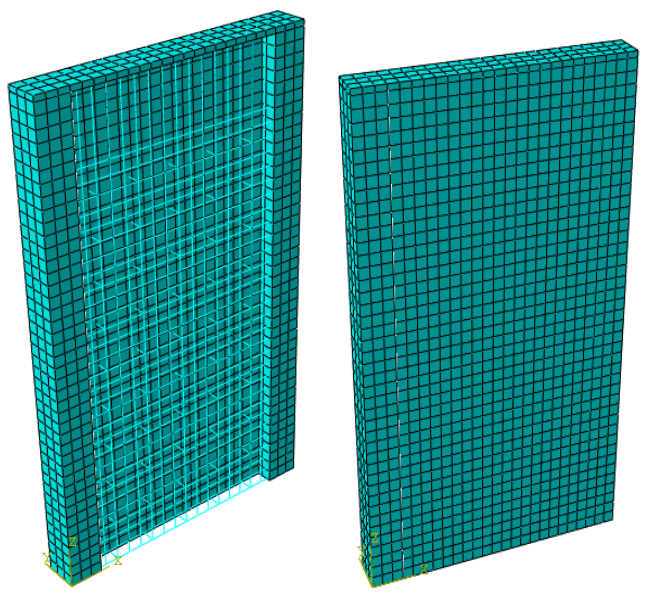

(b) GBW2

Fig. (8). Shapes of the specimens after elements have been meshed.

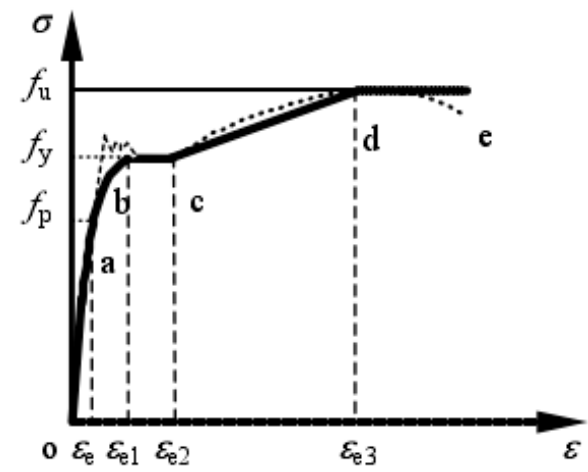

Fig. (9). Stress-strain curve of steels.

The natural vibration frequency which measured and calculated in elastic stage of two specimens are showed in Table 4. The relative error is within $6.0 \%$ and the measured results and calculated results are in good agreement.

The displacements at the top of the two specimens which measured and calculated in different stage are showed in Fig. (10). The measured results and calculated results are in good agreement. It proves that the elements which are chosen in this paper to conduct the time history analysis are reasonable.
Table 4. Natural vibration frequency measured and calculated in elastic stage of two specimens.

\begin{tabular}{|c|c|c|}
\hline & GBW1 & GBW2 \\
\hline \hline Measured results & 5.35 & 8.51 \\
\hline Calculated results & 5.05 & 8.07 \\
\hline relative error & $-4.91 \%$ & $-5.87 \%$ \\
\hline
\end{tabular}

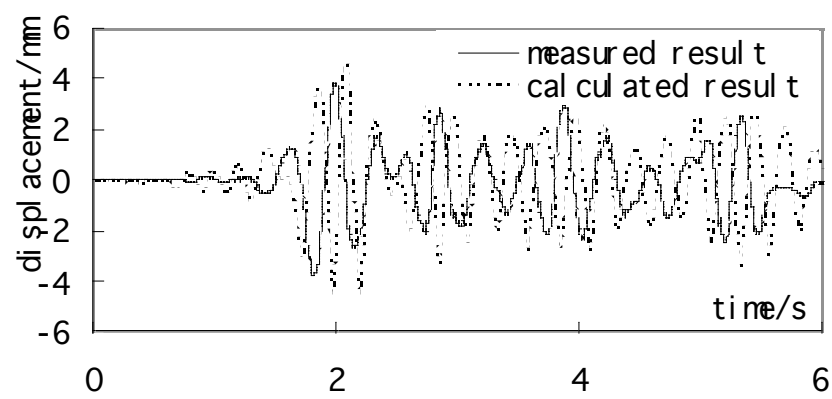

(1) GBW1 (0.286g)

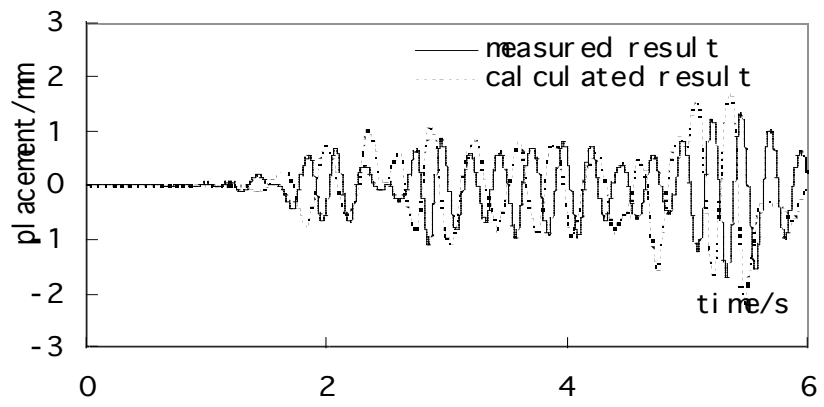

(2) GBW2 (0.323g)

Fig. (10). Displacements at the top of the two specimens which measured and calculated in different stage.

By observing the failure patterns of the two specimens, we can conclude that the steel-plates play a very prominent role in dissipating seismic energy. So we need to research that how to select the thickness of steel-plates is the most reasonable. In this paper, the author use the method of analysis above and change the thickness of steel-plates to calculate the displacements at the top of the two specimens in different seismic peak accelerations. The calculated results are showed in Table 5. From Table $\mathbf{5}$ we can see that when thickness of the steel-plates increase from $1 \mathrm{~mm}$ to $2 \mathrm{~mm}$ and from $2 \mathrm{~mm}$ to $4 \mathrm{~mm}$, the reduced amount of the displacements at the top of the specimens is relatively large. When the thickness of steel-plates is kept on increasing from $4 \mathrm{~mm}$ to $6 \mathrm{~mm}$, the reduced amount of the displacements is relatively small. Taking into account the price performance, it is not the thicker the better for the thickness of steel-plates.

\section{CONCLUSION}

The shear wall with CFST frame and embedded steelplate has a good seismic performance in shaking table test. The concrete outside the steel-plate can fully enhance stiffness of specimen. And the steel-plate show large resistance to deformation and excellent energy dissipating capacity in 
Table 5. Maximum displacements at the top of the specimens with different thickness of steel-plates in different seismic peak accelerations (mm).

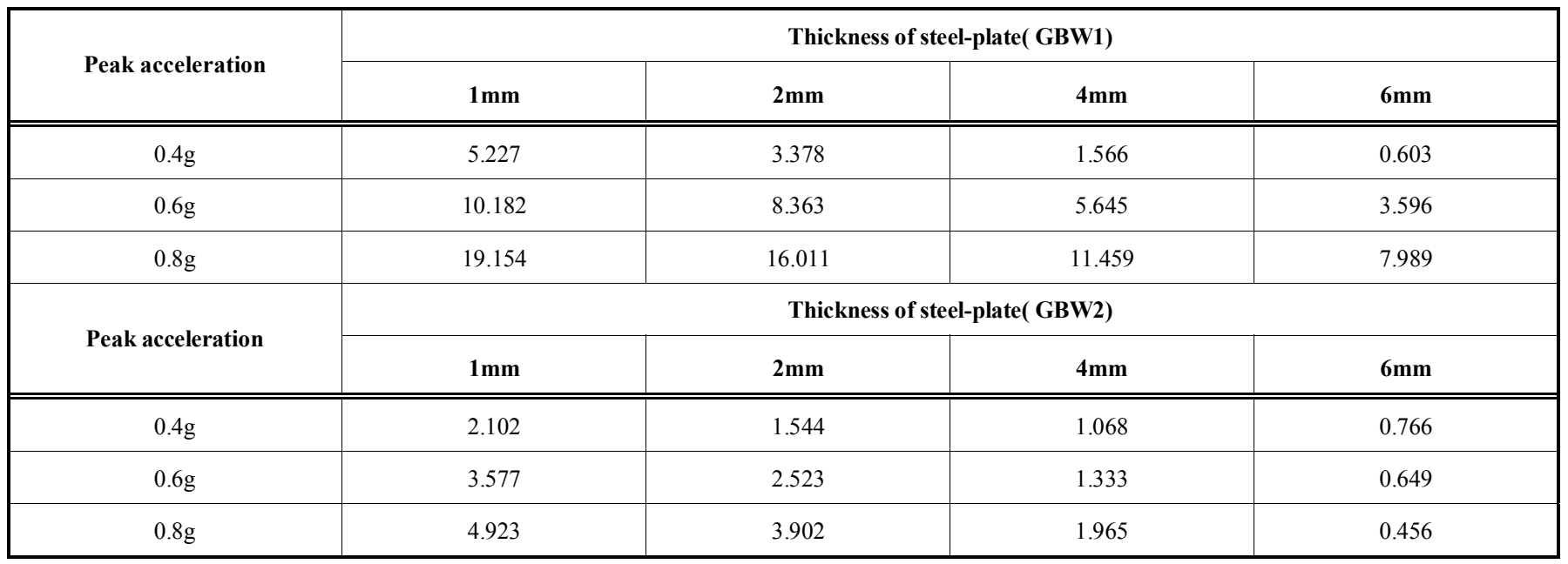

the experiment. The means which are chosen in this paper to conduct the time history analysis (including elastic stage and plastic stage) are reasonable and the calculated results are very similar to measured results. From the point of cost performance, it is not the thicker the better for the thickness of steel-plates.

\section{CONFLICT OF INTEREST}

The authors confirm that this article content has no conflict of interest.

\section{ACKNOWLEDGEMENTS}

This paper is subsidized by scientific research project of Inner Mongolia University of Technology (approved: X201414).

\section{REFERENCES}

[1] Y. Guo, M. Zhou, Q. Dong, "Hysteretic behavior of bucklingrestrained steel plate shear wall," Gong Cheng Li Xue, vol. 26, no. 2, pp. 108-114, 2009.
[2] K.M.A. Hossain "Design aspects of double skin profiled composite framed shear walls in construction and service stages," ACI Structural Journal, vol. 101, no. 1, pp. 94-102, 2004.

[3] A. Astaneh-Asl, Q. Zhao, "Cyclic behavior of steel shear wall systems", In: Proceedings - Annual Stability Conference, Seattle, 2002, pp. 21-36.

[4] M. Yamada, "Steel panel encased R.C composite shear walls", Composite Construction in Steel and Concrete II, New York, 1992, pp. 899-912.

[5] Y. Guo, Q. Dong, "Research and application of steel plate shear wall in high-rise buildings," Steel Construction, vol. 20, no. 1, pp. 96-102, 2005.

[6] H. Xie, "Performance and application of concrete filled steel tubes to high-rise building," Journal of Liaoning Institute of Technology, vol. 24 , no. 6 , pp. 53-55, 2004.

[7] Q. Chen, "Static Inelastic Analysis of Reinforced Concrete Coupled Shear Wall", M.S. thesis, Tsinghua University, China, 2002.

[8] Q. Li, "Study of mesh dividing methods in ANSYS," Journal of Shanghai Dianji University, vol. 9, no. 5, pp. 28-30, 2006.

[9] J. Bai, Q. Sun, Y. Guo, "Stress-analysis of a complex structure with the ANSYS system," Mechanical Science and Technology, vol. 22, no. 3, pp. 441-446, 2003.

[10] W. Liu "Research on Mechanism of Concrete-filled Steel Tubes Subjected to Local Compression", D.C. thesis, Fuzhou University, China, 2005.

(C) Yaohong et al.; Licensee Bentham Open.

This is an open access article licensed under the terms of the (https://creativecommons.org/licenses/by/4.0/legalcode), which permits unrestricted, noncommercial use, distribution and reproduction in any medium, provided the work is properly cited. 